\title{
Comparative study of mifepristone versus balloon catheter for cervical ripening and induction of labour in previous caesarean section
}

\author{
Krishna Dahiya $^{1}$, Nisha Yadav $^{1 *}$, Pushpa Dahiya ${ }^{1}$, Isha Nandal ${ }^{2}$
}

\begin{abstract}
${ }^{1}$ Department of Obstetrics and Gynecology, Pt. B. D. Sharma PGIMS, Rohtak, Haryana, India
${ }^{2}$ Department of Obstetrics and Gynecology, SGT Medical College Hospital and Research Institute, Gurugram, Haryana, India
\end{abstract}

Received: 24 March 2020

Accepted: 22 April 2020

\author{
*Correspondence: \\ Dr. Nisha Yadav, \\ E-mail: nonu834yadav@gmail.com
}

Copyright: () the author(s), publisher and licensee Medip Academy. This is an open-access article distributed under the terms of the Creative Commons Attribution Non-Commercial License, which permits unrestricted non-commercial use, distribution, and reproduction in any medium, provided the original work is properly cited.

\begin{abstract}
Background: The objective of this present study was to compare the efficacy of oral mifepristone and balloon catheter for cervical ripening and induction of labour in women with previous caesarean section.

Methods: This prospective study was conducted on 130 pregnant women with previous 1 caesarean section and term singleton pregnancy admitted for induction of labour. Sixty-five patients were induced with oral mifepristone (Group 1) and in another 65 transcervical balloon catheter (Group 2) was inserted for induction of labour. Both groups were than compared with respect to change in bishop score, induction to active phase interval, induction to delivery interval, dose of oxytocin in milliunits, mode of delivery, maternal complication and fetal outcomes.

Results: Change in bishop score after induction was more in mifepristone group than balloon catheter group $(\mathrm{p}=0.002)$. Favorable bishop score was more in Group $1(83.07 \%)$ than Group $2(66 \%), \mathrm{p}=0.05$. There was significant difference in mode of delivery between two groups, $61.53 \%$ in Group 1, and $32.3 \%$ in Group 2 delivered vaginally $(\mathrm{p}<0.001)$.

Conclusions: Present study showed that mifepristone is an alternative to balloon catheter for induction of labour in women with previous one caesarean section with poor bishop score.
\end{abstract}

Keywords: Balloon catheter, Induction, Previous caesarean, Mifepristone

\section{INTRODUCTION}

Induction of labour is defined as stimulation of regular uterine contractions before the spontaneous onset of labour with or without rupture of membrane after 28 weeks of gestational age using mechanical or pharmacological methods in order to generate progressive cervical dilatation and subsequent delivery. ${ }^{1}$ Current clinical practice guidelines support vaginal birth and trial of labour among women who have had a prior caesarean birth. ${ }^{2}$ The US National Institute of Health has examined the safety and outcome of trial of labour after caesarean section (TOLAC), recognizing that "it is a reasonable option for many women with a previous caesarean". 3 Induction of labour is carried out by various pharmacological and non-pharmacological methods. ${ }^{4}$ Mifepristone, also known as RU-486, is a 19 non-steroid with potent anti-progestogenic, anti-glucocorticoid and weak anti-androgenic effect. ${ }^{5}$ It increases the sensitivity of uterus to the actions of prostaglandins. It is characterized by rapid absorption and has a long half-life of 25-30 hours. Mechanical methods exert local pressure on cervix, overstretching the lower uterine segment and indirectly stimulating the secretion of prostaglandins. ${ }^{6}$ Both of these methods acts through different mechanism ultimately leading to cervical dilatation, effacement and initiation of labour. Therefore, the aim of present study is to compare efficacy of oral mifepristone and balloon catheter for cervical ripening and induction of labour in women with previous caesarean section. 


\section{METHODS}

This prospective, randomized study was conducted on 130 pregnant women with previous one caesarean section admitted to labour room of obstetrics and gynecology, Pt. B. D. Sharma Postgraduate Institute of Medical Sciences, Rohtak from September 2017-September 2018.

\section{Inclusion criteria}

- $\quad$ Singleton pregnancy

- Past history of 1 lower segment caesarean section

- Cephalic presentation

- Gestational age of 37-41 weeks

- Bishop score $<6$

- Adequate pelvis.

\section{Exclusion criteria}

- Women with inter delivery interval $<18$ months

- Premature rupture of membrane

- Multiple pregnancy

- Antepartum haemorrhage

- Chorioamnionitis

- Malpresentation

- Medical complication

- Previous history of myomectomy, classical caesarean section.

An informed and written consent was taken from each patient for inclusion into the study. Then a detailed case history was taken up from the patients and general physical, systemic, obstetrics and per vaginum examination including bishop score of the patient was noted down. Indication for induction was noted of each patient.

All routine antenatal investigation i.e. $\mathrm{Hb}, \mathrm{ABoRh}, \mathrm{HIV}$, VDRL, GCT, urine complete examinations, HBsAg were carried out. The eligible patients were randomly divided into 2 groups with the help of computer-generated random number. Group 1 pregnant women received mifepristone $400 \mathrm{mg}$ orally. In Group 2 women transcervical balloon catheter was inserted and filled with $30 \mathrm{ml}$ normal saline.

Repeat Bishop score was done after 24 hours or earlier if patient goes in labour. If bishop score was $>6$ then amniotomy was done followed by oxytocin infusion. Infusion was started at a dose of 2 milliunits per minute and increased every 30 min by 2 milliunits in both the groups till maximum of 20 milliunits per minute. Modified portogram was maintained for every patient. If bishop score was $<6$ after 24 hours of induction then the induction attempt was considered as failure and women was taken up for caesarean section.

\section{Primary outcome}

- Improvement in bishop score.

\section{Secondary outcome}

- Induction to active phase interval

- Induction to delivery interval

- Dose of oxytocin in milliunits

- Mode of delivery

- Maternal outcome such as postpartum haemorrhage, chorioamnionitis, retained placenta, need for blood transfusion, scar dehiscence/rupture were noted down in both the groups

- Neonatal details in reference to weight, fetal distress, Apgar score and NICU admission was noted down.

\section{Statistical analysis}

At the end of the study, the data was collected and statistically analysed by using SSPS version 20.0. The results were analysed by using Student t-test and Chisquare test. A p-value of $<0.05$ was considered significant.

\section{RESULTS}

One thirty women with eligible criteria were included in the study and were randomized into 2 groups (Table 1). Group 1 pregnant women received mifepristone $400 \mathrm{mg}$ orally.

In Group 2 women transcervical balloon catheter was inserted and filled with $30 \mathrm{ml}$ normal saline.

Repeat bishop score was done after 24 hours or earlier if patient goes in labour. Change in bishop score and favourable bishop score was noted and compared (Table 2) and was found to be better in Group 1.

Table 1: Baseline characteristics of patients in two groups.

\begin{tabular}{|llll|}
\hline Parameter & Group 1 & Group 2 & Statistical significance (p value) \\
\hline Age (years) & $25.35 \pm 2.77$ & $26.28 \pm 3.24$ & 0.182 \\
\hline POG & $39.46 \pm 1.18$ & $39.51 \pm 0.89$ & 0.704 \\
\hline Para 1 & $21.5 \%$ & $27.7 \%$ & 0.415 \\
\hline Previous VBAC & $9.2 \%$ & $4.6 \%$ & 0.344 \\
\hline Pre induction Bishop score & $2.35 \pm 0.51$ & $2.66 \pm 0.59$ & 0.082 \\
\hline
\end{tabular}


Table 2: Descriptive analysis of primary outcome in both groups.

\begin{tabular}{|llll|}
\hline Parameter & Group 1 & Group 2 & p value \\
\hline Change in bishop score & $3.95 \pm 1.64$ & $3.08 \pm 1.57$ & 0.002 \\
\hline Favorable bishop score & $83.07 \%$ & $66.15 \%$ & 0.050 \\
\hline
\end{tabular}

Table 3: Descriptive analysis of secondary outcome in both groups.

\begin{tabular}{|llll|}
\hline & Group 1 & Group 2 & p value \\
\hline Induction to active phase interval & $16.44 \pm 6.07$ & $15.22 \pm 5.81$ & 0.286 \\
\hline Induction to delivery interval & $24.71 \pm 7.67$ & $25.56 \pm 9.75$ & 0.579 \\
\hline Mean oxytocin duration(hour) & $4.85 \pm 1.41$ & $5.14 \pm 1.94$ & 0.570 \\
\hline NVD & $61.53 \%$ & $32.3 \%$ & $<0.001$ \\
\hline
\end{tabular}

Table 4: Maternal and neonatal outcomes.

\begin{tabular}{|llll|}
\hline & Group 1 & Group 2 & p value \\
\hline Scar tenderness & 0 & $1(1.53 \%)$ & 0.315 \\
\hline PPH & $8(12.3 \%)$ & $10(15.3 \%)$ & 0.539 \\
\hline Need of blood transfusion & $8(12.3 \%)$ & $10(15.3 \%)$ & 0.539 \\
\hline Fetal Apgar score at 1 min & $7.02 \pm 0.12$ & $6.97 \pm 0.25$ & 0.182 \\
\hline Fetal Apgar score at 5 min & $8.15 \pm 0.36$ & $8.77 \pm 0.43$ & 0.001 \\
\hline Baby weight & $2.75 \pm 0.48$ & $2.93 \pm 0.45$ & 0.03 \\
\hline Fetal distress & $14(21.5 \%)$ & $17(26.1 \%)$ & 0.537 \\
\hline NICU admission & $4(6.1 \%)$ & $9(13.8 \%)$ & 0.144 \\
\hline Scar rupture & 0 & 0 & - \\
\hline Chorioamnionitis & 0 & 0 & - \\
\hline
\end{tabular}

Secondary outcomes of study such as induction to active phase interval, induction to delivery interval, dose of oxytocin in milliunits, mode of delivery were studied and compared (Table 3) and there was no statistically significant difference except for number of normal vaginal delivery (NVD) which were $61.53 \%$ in Group 1 and $32.5 \%$ in Group $2(\mathrm{p}<0.001)$.

Maternal and perinatal outcomes, complications were also studied in detail (Table 4). Hence mifepristone is better alternative to balloon catheter for cervical ripening and successful VBAC in women with previous caesarean section.

Both groups were comparable with respect to maternal age, period of gestation at time of induction, parity, indication of induction of labour and pre induction bishop score. Primary outcome was better in Group 1 compared to group 2 with statistically significant results. These delivery outcomes were analysed in both groups and results were comparable with respect to induction to active phase interval, induction to delivery interval and mean oxytocin duration. But results were significantly better in group one $(61.53 \%)$ for normal vaginal delivery i.e. successful VBAC than Group $2(32.3 \%)$.

Maternal and neonatal complications were similar in both groups with no statistically significant difference.

\section{DISCUSSION}

Induction of labour is the commonest obstetric intervention. Induction implies stimulation of contractions before the spontaneous onset of labour. Induction of labour in previous caesarean section has very limited choices. In an effort to find a better way to induce labour in previous caesarean section various studies has been conducted all over the world. Present study was to compare mifepristone and balloon catheter for cervical ripening and induction of labour in previous one caesarean section. In the present study, pre induction bishop score were comparable. Change in bishop score was noted and compared. It was $3.95 \pm 1.64$ in mifepristone group and $3.08 \pm 1.57$ in balloon catheter group with significant difference on statistical analysis $(\mathrm{p}=0.002)$.

This signifies that induction with mifepristone results in greater changes in bishop score than balloon catheter group. In contrast Sharma et al noted post induction bishop score better in balloon catheter group than in mifepristone group $(p=0.000) .{ }^{7}$ It was observed that the mean induction to active phase of labour interval was $16.74 \pm 6.07$ hour in Group 1, and 15.22 \pm 5.81 hour in Group 2 but difference was not statistically significant ( $\mathrm{p}=0.286$, 95\% CI-1.299 to 4.336). No study has compared this interval. 
In this study, induction to delivery interval was

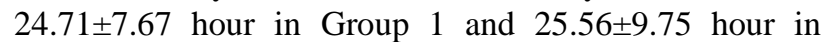
Group 2 respectively and the difference was statistically insignificant ( $\mathrm{p}=0.579, \mathrm{CI}-3.900$ to 2.187 ). In study by Stenlund et al the median time from the start of induction to delivery was shorter in mifepristone than placebo group (36-hour $23 \mathrm{~min}$. versus 53 hours $17 \mathrm{~min}$ ). ${ }^{8}$ Augmentation of labour with oxytocin was required in 22 women out of $41(54.9 \%)$ in Group 1 and fourteen $(66.7 \%)$ out of 21 in Group 2. Similar results were found in study by Lelaidier et al where mean dose of oxytocin requirement was lower in mifepristone group than placebo group $(\mathrm{p}<0.01){ }^{9}$

In present study, $40(61.53 \%)$ patients in Group 1 and twenty-one $(32.3 \%)$ in Group 2 had normal vaginal delivery, with statistically significant difference $(\mathrm{p}<0.001)$. Twenty-five $(38.46 \%)$ patients in Group 1 and $44(67.7 \%)$ women in Group 2 went for repeat caesarean section $(\mathrm{p}<0.001)$. However Sharma and coworkers observed no statistically significant difference in normal vaginal delivery or caesarean section in either group $\left(\mathrm{p}=0.242,0.331\right.$ respectively). ${ }^{7}$

Wing and other coworkers also observed 77 (87.5\%) mifepristone treated women and 46 (70.8\%) placebo treated women delivered vaginally 48 hours after start of treatment $(\mathrm{p}=0.01) .{ }^{10}$ Sharma et al compared vaginal delivery rates in mifepristone treated group, 53 out of 72 (73.6\%) and spontaneous onset of labour group, 285 out of $346(82.3 \%), p=0.076 .^{11}$ Meetei et al found lower rates of vaginal delivery in foley group $(55.7-64.7 \%)$ than in low dose oxytocin group $(74.7 \%){ }^{12}$

Maternal and neonatal outcomes were similar in both groups.

\section{CONCLUSION}

Present study indicates that induction of labour with mifepristone and balloon catheter seems to be safe in women with previous one caesarean section. Mifepristone was associated with higher rates of cervical ripening and vaginal delivery than balloon catheter. However, there was no significant difference in induction to active phase of labour interval, induction-delivery interval and dose of oxytocin used in both groups.

Maternal and fetal complications were similar in both groups. Hence, mifepristone may be offered to women with previous one caesarean section for cervical ripening and induction of labour. However larger study with a greater number of patients is required to reach statistically significant conclusion.
Funding: No funding sources

Conflict of interest: None declared

Ethical approval: The study was approved by the Institutional Ethics Committee

\section{REFERENCES}

1. Mishra R. Ian Donald's Practical obstetric problems. $7^{\text {th }}$ ed. New Delhi: BI publication. Chapter 24: Management of labour; 2014:584.

2. Hemlatha KR, Swetha D. Case series of foley's induction in patients with previous caesarean. Int $\mathbf{J}$ Reprod Contracept Obstet Gynecol. 2017;6:1635-8.

3. National Institutes of Health Consensus Development Conference Panel. National Institutes of Health Consensus Development conference statement: vaginal birth after caesarean: new insights. Obstet Gynecol. 2010;115:1279-95.

4. Leduc D, Biringer A, Lee L, dy J. Clinical practice obstetrics committee. Induction of labour. J Obstet Gynaecol Can 2013;35:840-60.

5. Heinkinheimo O. Clinical pharmacokinetics of mifepristone. Clin Pharmacokinet. 1997;33(1):7-17.

6. Mozurkewich EL, Chilimigras JL, Berman DR, Perni UC, Romero VC, King VJ, et al. Methods of induction of labour: a systemic review. BMC Preg Childbirth. 2011;11:84-6.

7. Sharma C, Soni A, Gupta A, Verma A, Verma S. Mifepristone versus balloon catheter for labour induction in previous caesarean. Arch Gynecol Obstet. 2017;296:241-8.

8. Stenlund PM, Ekman G, Aedo AR, Bygdeman M. Induction of labour with mifepristone- a randomized, double-blind study versus placebo. Acta Obstet Gynecol Scand. 1999;78(9):793-8.

9. Lelaidier C, Baton C, Benifla JL, Fernandez H, Bourget $\mathrm{PH}$, Frydman R. Mifepristone for labour induction after previous caesarean section. $\mathrm{Br} \mathrm{J}$ Obstet Gynaecol. 1994;101(6):501-3.

10. Wing DA, Fassett MJ, Mishell DR. Mifepristone for pre-induction cervical ripening beyond 41 weeks, gestation: a randomized controlled trial. Obstet Gynecol. 2000;96:543-8.

11. Sharma C, Soni A, Soni PK, Verma S, Verma A, Gupta A. A retrospective case-control study evaluating the role of mifepristone for induction of labour in women with previous caesarean section. J Obstet Gynecol India. 2016;66:30-7.

12. Meetei LT, Suri V, Aggarwal N. Induction of labour in patients with previous caesarean Section with unfavorable cervix. J Med Soc. 2014;28:29-33.

Cite this article as: Dahiya K, Yadav N, Dahiya P, Nandal I. Comparative study of mifepristone versus balloon catheter for cervical ripening and induction of labour in previous caesarean section. Int J Reprod Contracept Obstet Gynecol 2020;9:2504-7. 